\title{
Satisfaction and maternal postnatal adjustments following different modes of delivery
}

\author{
Manorama Eti, Sunitha C.*, Sarojamma C., Sai Lakshmi M. P. A.
}

Department of Obstetrics and Gynecology, Rajarajeswari Medical College and Hospital, Bangalore, Karnataka, India

Received: 21 November 2019

Accepted: 30 December 2019

*Correspondence:

Dr. Sunitha C,

E-mail: drmanoramaeti19@yahoo.in

Copyright: ( ) the author(s), publisher and licensee Medip Academy. This is an open-access article distributed under the terms of the Creative Commons Attribution Non-Commercial License, which permits unrestricted non-commercial use, distribution, and reproduction in any medium, provided the original work is properly cited.

\begin{abstract}
Background: Childbirth has a profound influence in a women's life. One factor that has been more consistently identified as influencing the women's physical and psychological symptoms following childbirth is the mode of birth. This study aims at figuring out on women's satisfaction with their mode of delivery and what difficulties they faced in the immediate postnatal period accordingly.

Methods: All women who delivered between the period $1^{\text {st }}$ July 2019 to $1^{\text {st }}$ August 2019 were interviewed with a pretested semi structured questionnaire on postnatal day two. Patient was asked how much they were satisfied with their mode of delivery, immediate postnatal adjustments like ambulation, holding the baby first time, initiation of breastfeeding and pain score following different modes of delivery. The data was analysed to find out which mode of delivery made women more comfortable in the immediate postnatal period.

Results: A total $97.1 \%$ women were satisfied with the support they got from health care professionals during labour. But when compared, spontaneous vaginal delivery group were satisfied with their mode of delivery (P-value- 0.0005 highly significant) than the rest. Women who had vaginal delivery were ahead of caesarean group in terms of ambulation, holding the baby, initiation of breastfeeding and were well adjusted in their postnatal period.

Conclusions: Authors conclude that women in our study were more satisfied with spontaneous vaginal delivery than caesarean section which was reflected in their immediate postnatal adjustments. As obstetricians' authors need to understand the empowering effects of the psychological experience of vaginal delivery. The benefits of this process can be maximized through good communication skills and emotional support for women, enhancing their confidence to deliver normally so that caesarean section is done only when really indicated.
\end{abstract}

Keywords: Caesarean section, Childbirth, Postnatal adjustments, Satisfaction, Vaginal delivery

\section{INTRODUCTION}

Childbirth has a profound influence in a women's life. In India, childbirth is considered as "rebirth" for a woman. Are our women psychologically satisfied with their mode of delivery? There is limited research on women's psychological experience and satisfaction, following delivery. This study aims at figuring out on women's satisfaction with their mode of delivery and what difficulties they faced in the immediate postnatal period accordingly. Postnatal period is the time period that starts immediately following childbirth and lasts up to 6 weeks. In India a great level of importance is placed on postnatal care. With the joy of welcoming the new-born women also experience the messy postpartum bleeding along with painful episiotomy or the C-section incision. They will be figuring out how to breastfeed the neonate. Women suffer from weight gain, fatigue, headaches and poor sleep. Hormonal imbalance also impacts their mood, and they may experience feelings of depression and anxiety. One factor that has been more consistently identified as influencing the women's physical and 
psychological symptoms following childbirth is the mode of birth. Childbirth is a complex phenomenon involving wide range of medical and social factors which influence women's experiences and outcomes. Mode of birth is found to be in association with maternal postnatal adjustment. An increase in births by Caesarean Section globally, has highlighted concerns that women who experience caesarean section may have poorer physical and psychosocial adjustment after birth. ${ }^{1}$

Objective of this study was to determine the satisfaction and immediate maternal postnatal adjustments following different modes of delivery at a tertiary care hospital, Bangalore, Karnataka.

\section{METHODS}

The study was done in postnatal ward. All women who delivered between the period $1^{\text {st }}$ July 2019 to $1^{\text {st }}$ August 2019 were interviewed with a pretested semi structured questionnaire on postnatal day two. Patient was asked how much they were satisfied with their mode of delivery. The questionnaire also included questions pertaining to postnatal adjustments following different modes of delivery. Immediate postnatal adjustment was assessed in terms of when they could hold the baby for the first time, initiate breastfeeds, ambulate, and the pain they tolerated following different modes of delivery. Data was collected by interview method and analysed using SPSS.

\section{Inclusion criteria}

- A total 105 women who had term delivery at Rajarajeswari Medical College and Hospital between the period $1^{\text {st }}$ July 2019 to $1^{\text {st }}$ August 2019.

\section{Exclusion criteria}

- Women who were unable to comprehend
- Women with stillbirths and abortions

- Women with preterm delivery.

\section{Statistical analysis}

The collected data were analysed with IBM.SPSS statistics software 23.0 Version. To describe about the data descriptive statistics frequency analysis, percentage analysis was used for categorical variables and the mean and SD were used for continuous variables. To find the significance in categorical data Chi-Square test was used. In the above statistical tool, the probability value .05 is considered as significant level.

\section{RESULTS}

\section{Age of postnatal women}

As authors see the age of the study population (Table 1), out of 105 women, $49(46.6 \%)$ of the women who delivered were in between age group of 21 to 25 years. Among them 38 had spontaneous vaginal delivery. Next majority group was between 26-30 years which constituted $34.28 \%$. Authors had 9 (8.5\%) women in the study population who were between 18-20 years. Among 105 women $56(53.3 \%)$ were primiparous and 49 (46.6\%) were multipara women.

\section{Different modes of delivery in the study population}

With reference to table number 2, spontaneous vaginal delivery accounted for $70.5 \%$ of delivery and contributed to the major chunk of the study population. In our study, 4 $(3.8 \%)$ women delivered by elective caesarean section. All being primigravidae, 3 of them were advised elective caesarean for breech presentation. The fourth caesarean was done for placenta previa (type 2 posterior). Instrumental delivery accounted for $3.8 \%$ of the study population, all of them indicated poor maternal bearing down efforts.

Table 1: Age of postnatal women.

\begin{tabular}{|c|c|c|c|c|c|c|}
\hline Age & $\begin{array}{l}\text { Vaginal } \\
\text { delivery }\end{array}$ & Emergency LSCS & Elective LSCS & $\begin{array}{l}\text { Instrumental } \\
\text { deliveries }\end{array}$ & Number & Percent \\
\hline $18-20$ years & 08 & 1 & - & - & 09 & $8.57 \%$ \\
\hline $21-25$ years & 38 & 6 & 4 & 1 & 49 & $46.66 \%$ \\
\hline 26-30 years & 24 & 10 & - & 2 & 36 & $34.28 \%$ \\
\hline$>30$ years & 04 & 6 & - & 1 & 11 & $10.50 \%$ \\
\hline Total & 74 & 23 & 4 & 4 & 105 & $100 \%$ \\
\hline Total & & \multicolumn{2}{|c|}{105} & \multicolumn{3}{|c|}{$100.0 \%$} \\
\hline
\end{tabular}

A total 23 of them underwent emergency LSCS out of which $10(43.4 \%)$ of them were for previous LSCS in labour, not willing for vaginal birth after caesarean section (VBAC). 8 (34.7\%) of them for foetal distress, 3
(13.04\%) for secondary arrest of dilatation of cervix and remaining $2(8.6 \%)$ for failed induction of labour.

Satisfaction with the care given during the process of delivery 
Satisfaction with the care given during the process of delivery was assessed in terms of choices offered to them about different modes of delivery and support given to them by health care professionals during the process. Majority of women, $89(84.8 \%)$ were happy that they were explained about different modes of delivery and were given an opportunity to choose. 102 (97.1\%) women were satisfied with support they got from health care professionals during labour. They said they were well communicated and had full confidence with the staff.

Comparison of postnatal adjustments following different modes of delivery in terms of ambulation, holding the baby, initiation of breastfeeding and pain assessment.

\section{A. Ambulation following delivery}

When compared with vaginal and caesarean births in terms of ambulation (Table 3), all the patients who delivered vaginally (spontaneous and instrumental) were ambulating by 2 hours of childbirth. Only $2(50 \%)$ patients in the elective and $6(26.08 \%)$ patients in the emergency caesarean section group could ambulate within 12 hours.

\section{B. Holding the baby for the first time}

Holding the baby was an indicator of the time between the baby's birth and when the mother first held the baby (Table 4). Within half an hour, 75.67\% women who had spontaneous vaginal delivery could hold their babies. All women who delivered vaginally (both spontaneous and instrumental) could hold their babies by 2 hours. Since majority of women in the vaginal delivery group were satisfied and happy with their mode of delivery and had mild pain they were very enthusiastic to hold their babies and to initiate breastfeeding.

Table 2: Different modes of delivery.

\begin{tabular}{|lll|}
\hline Mode of delivery & Number & Percentage \\
\hline Spontaneous & 74 & $70.5 \%$ \\
\hline Elective LSCS & 4 & $3.8 \%$ \\
\hline Emergency LSCS & 23 & $21.9 \%$ \\
\hline Instrumental deliveries & 4 & $3.8 \%$ \\
\hline
\end{tabular}

In the caesarean group, due to separation of the mother and baby for various reasons and also because of the pain of the surgery, only $25 \%$ in the elective group and $43.47 \%$ in the emergency group could hold the baby within one hour of childbirth.

Table 3: Ambulation in postnatal period.

\begin{tabular}{|llll|}
\hline Mode of delivery & Time & Number & Percentage \\
\hline \multirow{2}{*}{ Spontaneous } & Within 1 hour & 12 & $16.16 \%$ \\
\cline { 2 - 4 } & $1-2$ hours & 62 & $83.78 \%$ \\
\hline \multirow{2}{*}{ Elective LSCS } & Within 12 hours & 2 & $50 \%$ \\
\cline { 2 - 4 } Emergency LSCS & $12-24$ hours & 2 & $50 \%$ \\
\hline \multirow{2}{*}{ Instrumental delivery } & Within 12 hours & 6 & $26.08 \%$ \\
\cline { 2 - 4 } & $12-24$ hours & 2 & $73.91 \%$ \\
\hline
\end{tabular}

Table 4: Holding the baby for the first time.

\begin{tabular}{|llll|}
\hline Mode of delivery & Time & Number & Percentage \\
\hline \multirow{2}{*}{ Spontaneous } & Within half an hour & 56 & $75.67 \%$ \\
\cline { 2 - 4 } & $1-2$ hours & 18 & $24.32 \%$ \\
\hline \multirow{2}{*}{ Elective LSCS } & within1hour & 1 & $25 \%$ \\
\cline { 2 - 4 } & $1-2$ hours & 3 & $75 \%$ \\
\hline \multirow{2}{*}{ Emergency LSCS } & within1hour & 10 & $43.47 \%$ \\
\cline { 2 - 4 } Instrumental deliveries & $1-2$ hours & 13 & $56.52 \%$ \\
\cline { 2 - 4 } & Within half an hour & 2 & $50 \%$ \\
\hline
\end{tabular}

\section{Initiation of breastfeeding}

In our study, those patients who delivered by caesarean section could not initiate breastfeeding within an hour compared to those who delivered vaginally (Table 5).
$75.67 \%$ of women who delivered vaginally could breastfeed the baby within an hour. Among 4 patients who delivered by elective caesarean section, only 1 $(25 \%)$ could breastfeed within an hour. 2 babies who delivered by elective caesarean section were shifted to 
NICU for observation in view of transient tachypnoea of new-born. The fourth baby could not be breastfed within an hour as the mother complained severe pain postoperatively.

Table 5: Initiation of breastfeeding.

\begin{tabular}{|llll|}
\hline \multirow{2}{*}{ Sode of delivery } & Time & Number & Percentage \\
\cline { 2 - 4 } & Within 1 hour & 56 & $75.67 \%$ \\
\cline { 2 - 4 } Elective LSCS & $1-2$ hours & 18 & $24.32 \%$ \\
\cline { 2 - 4 } & Within 1 hour & 1 & $25 \%$ \\
\cline { 2 - 4 } Emergency LSCS & $1-2$ hours & 3 & $75 \%$ \\
\hline \multirow{2}{*}{ Instrumental delivery } & Within 1 hour & 9 & $39.13 \%$ \\
\cline { 2 - 4 } & $1-2$ hours & 2 & $50.86 \%$ \\
\hline
\end{tabular}

Table 6: Pain score following different modes of delivery.

\begin{tabular}{|llll|}
\hline \multirow{3}{*}{ Mode of delivery } & Pain score & Number & Percentage \\
\cline { 2 - 4 } & Mild & 61 & $82.43 \%$ \\
\cline { 2 - 4 } & Moderate & 13 & $17.56 \%$ \\
\hline \multirow{2}{*}{ Elective LSCS } & Severe & - & - \\
\hline \multirow{2}{*}{ Emergency } & Mild & 2 & $50 \%$ \\
\cline { 2 - 4 } & Moderate & 2 & $50 \%$ \\
\cline { 2 - 4 } & Severe & - & - \\
\hline \multirow{2}{*}{ Instrumental } & Mild & 6 & $26.08 \%$ \\
\cline { 2 - 4 } & Moderate & -17 & - \\
\cline { 2 - 4 } & Severe & - & $25 \%$ \\
\hline & Mild & 1 & $\%$ \\
\cline { 2 - 4 } & Moderate & - & - \\
\cline { 2 - 4 } & Severe & - & \\
\hline
\end{tabular}

Out of 23 patients who delivered by emergency LSCS, only $9(39.13 \%)$ patients could breastfeed within first hour of birth. Rest 14 (60.86\%) of them could not do so as they had difficulty in initiating breastfeeding for various reasons.

\section{Pain assessment following different modes of delivery}

As authors all know pain is a significant complaint in the postpartum period. Incisional pain in caesarean section and perineal soreness in women with vaginal delivery are common complaints in the immediate postpartum period. There are multiple validated tools available to assess pain during postpartum. One among them is Numerical Rating Scale (NRS). In our study, pain was measured using NRS scale. As shown in the picture below (Figure 1), 0 indicates no pain, scores 1-3 indicate mild pain (nagging, annoying, interfering little with activities of daily living ADL), scores 4-6 indicate moderate pain (interferes significantly with ADLs) and scores 7-10 indicate severe pain (disabling; unable to perform ADLs). ${ }^{2}$

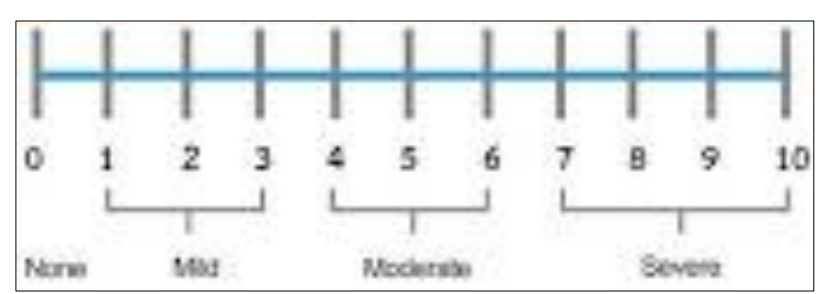

Figure 1: Numerical rating scale.

In our study, pain experienced by postnatal women following different modes of delivery was measured using numerical rating scale (NRS) (Table 6). 82.4\% women who delivered by spontaneous vaginal delivery and $25 \%$ of women who had instrumental delivery experienced mild pain respectively. Rest $17.5 \%$ in spontaneous delivery and $75 \%$ of instrumental delivery group had moderate pain. They complained that the vaginal area was sore in the immediate period following childbirth and took extra doses of analgesics. In the caesarean group, $50 \%$ in the elective group and $73.91 \%$ in the emergency group suffered from moderate pain. 
Table 7: Comparison of women's satisfaction with different modes of delivery.

\begin{tabular}{|c|c|c|c|c|c|c|}
\hline \multirow{2}{*}{ Mode of delivery } & & \multicolumn{2}{|c|}{ Satisfaction } & \multirow{2}{*}{ Total } & \multirow{2}{*}{$\chi^{2}$ - value } & \multirow{2}{*}{ p-value } \\
\hline & & No & Yes & & & \\
\hline \multirow{2}{*}{ Elective LSCS } & Count & 4 & 0 & 4 & \multirow{10}{*}{27.384} & \multirow{10}{*}{$0.0005^{* *}$} \\
\hline & $\%$ & $100.0 \%$ & $0.0 \%$ & $100.0 \%$ & & \\
\hline \multirow{2}{*}{ Emergency LSCS } & Count & 11 & 12 & 23 & & \\
\hline & $\%$ & $47.8 \%$ & $52.2 \%$ & $100.0 \%$ & & \\
\hline \multirow{2}{*}{ Spontaneous } & Count & 16 & 58 & 74 & & \\
\hline & $\%$ & $28.1 \%$ & $71.9 \%$ & $100.0 \%$ & & \\
\hline \multirow{2}{*}{ Instrumental } & Count & 4 & 0 & 4 & & \\
\hline & $\%$ & $100.0 \%$ & $0.0 \%$ & $100.0 \%$ & & \\
\hline \multirow{2}{*}{ Total } & Count & 35 & 70 & 105 & & \\
\hline & $\%$ & $33.3 \%$ & $66.7 \%$ & $100.0 \%$ & & \\
\hline
\end{tabular}

** Highly significant at $\mathrm{P}<0.01$ level.

Also $75 \%$ of patients of instrumental delivery group had moderate pain. Thus, authors can see that women who delivered vaginally experienced less pain in immediate postpartum than those who delivered by caesarean section.

\section{DISCUSSION}

\section{Satisfaction with the mode of delivery}

Obstetricians should not only concentrate on the delivery aspects during the process but also understand the emotional and psychosocial needs of labouring women. The birth experience could be positive and empowering, or negative and traumatising. ${ }^{3}$ Women who receive good emotional support from their health care professionals during labour have a positive birth experience. Women in labour should be well communicated and actively involved in all the decisions. Even if there is a healthy mother and a healthy newborn, lack of communication and lack of knowledge about physiology of labour results in a traumatising birth experience. Understanding the psychological experience in vaginal birth can contribute to promotion of healthy, happy family relationships in the longer term. ${ }^{3}$ When authors compare satisfaction following different modes of delivery, spontaneous vaginal delivery group were satisfied with their mode of delivery (P-value-0.0005 highly significant) than the rest (Table 7). Elective LSCS group were not at all satisfied with their mode of delivery. They wanted a trial of labour. In emergency LSCS group, $52.2 \%$ of them were satisfied. Instrumental delivery group were not satisfied with their mode of delivery. They found it very traumatic.

Women who delivered vaginally described a sense of joy and pride. Some women were also surprised how effectively their body tolerated labour pains. This ability to manage labour pain positively influenced their confidence in becoming a mother.

Caesarean section is now one of the most common surgical procedures performed, with many parts of the world having seen a sharp rise in their caesarean section rates in recent years. In our study population maximum emergency LSCS was because of previous LSCS in labour not willing for VBAC (Vaginal Birth After Caesarean section). Our study correlates with study done by Fitzpatrick KA et al in UK, wherein women embark for a repeat caesarean section with a history of previous caesarean section. ${ }^{4}$ Though the maternal and perinatal morbidity is present with VBAC the absolute risk of adverse outcomes is small and this information can be used to counsel and manage the increasing number of women with previous caesarean section. ${ }^{4}$

\section{Ambulation}

According to guidelines., bladder catheter should be removed within 12 hours of surgery and early ambulation on day 1 (or earlier from $6^{\text {th }}-8^{\text {th }}$ hour) with help is recommended. ${ }^{5}$ Early ambulation improves respiratory function and tissue oxygenation. Also reduces risk of thromboembolism and shortens length of hospital stay. ${ }^{6}$ When asked about the hindering factor, all of them attributed to pain. Authors would like to say that, caesarean section is on the rising trend and most commonly performed surgery worldwide. If pain is not managed adequately it leads to delayed functional recovery which inturn delays early discharge to home. Authors can conclude that pain management post caesarean should be done properly in view of rapid recovery to normal. ${ }^{7}$

\section{Breastfeeding}

Authors all are aware that one of the measures taken to reduce neonatal death is early initiation of breast feeding. According to National Family Health Survey (NHFS-4), only $41.6 \%$ of newborns are breastfed within an hour. ${ }^{8}$ According to $\mathrm{WHO}$, breastfeeding should be initiated within an hour of birth. ${ }^{9}$ Our study correlated with Hobbs AJ et al wherein they also found that women who delivered by emergency LSCS (41\%) had more difficulty in initiating breastfeeding than those women who 
delivered vaginally (29\%). ${ }^{10}$ In another study done by Rowe-Murray $\mathrm{HJ}$ et al, they have described C-section as a persistent barrier to early initiation of breastfeeding. ${ }^{11}$ Since C-sections are on the rising trend, the solution to this problem is putting the babies on mother's breast for skin to skin contact/feeding during caesarean section only when feasible. This will provide the mother an opportunity to hold and feed the baby and a sense of empowerment and control. ${ }^{12}$

\section{Pain management}

As authors saw in our study, women who delivered by caesarean section and who had instrumental delivery had more pain scores than who had spontaneous vaginal delivery. Management of pain in postpartum period is of major concern. If this is not done properly, it hampers mother and baby bonding. ${ }^{13}$ As discussed above inadequate pain management can prevent early ambulation thus increasing the risk of thromboembolism and later may continue as chronic pain that may last beyond postpartum. ${ }^{13}$

\section{CONCLUSION}

Authors conclude that women in our study were happier and more satisfied with spontaneous vaginal delivery than caesarean section which was reflected in their adjustments in the immediate postnatal period. Giving birth physiologically is an intense and transformative psychological experience that generates a sense of empowerment. As obstetricians authors need to understand the empowering effects of the psychological experience of vaginal birth. The benefits of this process can be maximised through good communication skills and emotional support for women, enhancing their confidence in their ability to deliver normally without disturbing physiology unless there is a compelling need.

Also, on the other hand caesarean section is like a double-edged sword, underuse can result in increased perinatal morbidity and mortality. Overuse has no added benefits. Hence the need of the hour is optimising the need of caesarean section. In a developing country like India, medical faculty should be properly trained so that they perform caesarean section only when indicated. Once women are satisfied with their delivery, they become confident to take up all the challenges of motherhood whether it may be in the immediate postpartum or in the future.

Funding: No funding sources Conflict of interest: None declared

Ethical approval: The study was approved by the Institutional Ethics Committee

\section{REFERENCES}

1. Alderdice F, Henderson J, Opondo C, Lobel M, Quigley M, Redshaw M. Psychosocial factors that mediate the association between mode of birth and maternal postnatal adjustment: findings from a population-based survey. BMC Women's Health. 2019;19(1):42.

2. Instruments PI. National Institutes of Health. Warren Grant Magnuson Clinical Center, 2003. Arch. 2012:914.

3. Olza I, Leahy-Warren P, Benyamini Y, Kazmierczak M, Karlsdottir SI, Spyridou A, et al. Women's psychological experiences of physiological childbirth: a meta-synthesis. BMJ Open. 2018;8(10):e020347.

4. Fitzpatrick KE, Kurinczuk JJ, Bhattacharya S, Quigley MA. Planned mode of delivery after previous cesarean section and short-term maternal and perinatal outcomes: a population-based record linkage cohort study in Scotland. PLoS Med. 2019;16:9.

5. Fuchs F, Benhamou D. Post-partum management after cesarean delivery. Guidelines for clinical practice. J Gynecol Obstet Biol Reprod. 2015;44(10):1111-7.

6. Macones GA, Caughey AB, Wood SL, Wrench IJ, Huang J, Norman M, et al. Guidelines for postoperative care in cesarean delivery: enhanced recovery after surgery (ERAS) society recommendations (part 3). Am J Obstet Gynecol. 2019.

7. Sutton CD, Carvalho B. Optimal pain management after cesarean delivery. Anesthesiol Clin. 2017;35(1):107-24.

8. National Family Health Survey, India (NFHS-4), 201516. Available at: http://rchiips.org/NFHS/NFHS4Reports/India.pdf.

9. World Health Organization. Breastfeeding: The Key to Survival and Beyond, 2010. Available at: http://new.paho. org/hq/dmdocuments/2010/Eight\% $\%$ 20English \%20FINAL.pdf. Accessed on $15^{\text {th }}$ October 2017.

10. Hobbs AJ, Mannion CA, McDonald SW, Brockway M, Tough SC. The impact of caesarean section on breastfeeding initiation, duration and difficulties in the first four months postpartum. BMC Preg Childbirth. 2016;16(1):90.

11. Rowe-Murray HJ, Fisher JR. Baby friendly hospital practices: cesarean section is a persistent barrier to early initiation of breastfeeding. Birth. 2002;29(2):124-31.

12. Dudeja S, Sikka P, Jain K, Suri V, Kumar P. Improving first-hour breastfeeding initiation rate after cesarean deliveries: a quality improvement study. Indian Pediatr. 2018;55(9):761-4.

13. Fahey JO. Best practices in management of postpartum pain. The J Perinatal Neonat Nurs. 2017;31(2):126-36.

Cite this article as: Eti M, Sunitha C, Sarojamma C, Sai Lakshmi MPA. Satisfaction and maternal postnatal adjustments following different modes of delivery. Int J Reprod Contracept Obstet Gynecol 2020;9:640-5. 